\title{
OS BENEFICIÁRIOS DA OPÇÃO DE RECORRER AO FORO DA RESIDÊNCIA HABITUAL DO CREDOR NO REGULAMENTO \\ SOBRE OBRIGAÇÕES DE ALIMENTOS - A INVERSÃO DA JURISPRUDÊNCIA NO CASO WV CONTRA LANDKREIS HAMBURG
}

\author{
THE BENEFICIARIES OF THE OPTION TO RESORT \\ TO THE JURISDICTION OF THE CREDITOR'S HABITUAL \\ RESIDENCE IN THE MAINTENANCE OBLIGATIONS \\ REGULATION - THE REVERSAL OF JURISPRUDENCE IN \\ THE JUDGMENT WV VERSUS LANDKREIS HARBURG
}

\author{
Anabela Susana de Sousa Gonçalves \\ Professora Associada da \\ Escola de Direito da Universidade do Minho
}

Recibido: 16.11.2020 / Aceptado: 14.12.2020

DOI: https://doi.org/10.20318/cdt.2021.6019

\begin{abstract}
Resumo: Este breve comentário analisa a decisão do TJUE Wv contra Landkreis Hamburg e a controvérsia que foi dirimida sobre a possibilidade de uma entidade pública recorrer ao tribunal do lugar da residência habitual do credor de alimentos, de acordo com o art. $3^{\circ}$ al. b) do Regulamento Sobre Obrigações Alimentares, numa ação de regresso contra o devedor de alimentos relativa ao crédito de alimentos que the foi transmitido por sub-rogação legal, em resultado de prestações de assistência social.

Palavras-chave: Regulamento sobre Obrigações Alimentares, residência habitual do credor de alimentos, artigo 3 (3).
\end{abstract}

\begin{abstract}
Abstact: This brief commentary analyses the judgment of the ECJ, Wv against Landkreis Hamburg, and the controversy that was settled over the possibility of a public entity appealing to the court of the creditor's habitual residence, according to Article 3 (b) of the Maintenance Obligations Regulation, in an action for recovery of maintenance brought against the debtor concerning the maintenance credit that was transmitted to him by legal subrogation, as a result of social assistance benefits.
\end{abstract}

Keywords: Maintenance Obligations Regulation, creditor's habitual residence, Article 3 (b).

Sumário: I. O caso Wv contra Landkreis Hamburg. II. O Regulamento Sobre Obrigações Alimentares. III. A norma de competência internacional do art. $3^{\circ}$ do Regulamento Sobre Obrigações Alimentares. IV. A controvérsia em torno da al. b) do art. $3^{\circ}$ do Regulamento Sobre Obrigações Alimentares. 


\section{O caso Wv contra Landkreis Hamburg}

1. O caso Wv contra Landkreis Hamburg, decidido pelo Tribunal de Justiça da União Europeia (TJUE) em 17 de setembro de $2020^{1}$, envolve a aplicação do art. $3^{\circ}$, al. b), do Regulamento relativo à competência, à lei aplicável, ao reconhecimento e à execução das decisões e à cooperação em matéria de obrigações alimentares (Regulamento sobre Obrigações Alimentares). Wv, idosa e residente na Alemanha, era titular de uma pensão de alimentos em relação ao seu filho, residente na Áustria. A mãe de Wv recebeu, a partir de abril de 2017, prestações de assistência social concedidas pelo Distrito de Hamburgo.

2. Nos termos do Código Civil alemão, o Distrito de Hamburgo considerou-se sub-rogado no direito da beneficiária da assistência social face ao seu filho, relativamente às prestações alimentares. Assim sendo, propôs uma ação de regresso em matéria alimentos contra Wv, para recuperar os créditos alimentares de que era titular em sub-rogação da mãe de Wv, no Tribunal Regional Superior de Colónia, enquanto tribunal do local em que o credor tem a sua residência habitual, nos termos do art. $3^{\circ}$, al. b), do Regulamento sobre Obrigações Alimentares. Ora, este Tribunal considerou que a competência prevista no art. $3^{\circ}$, al. b) era reservada exclusivamente à pessoa singular à qual era devida a pensão de alimentos.

3. Esta decisão foi objeto de recurso para o Tribunal Regional Superior de Colónia, que tomou uma decisão contrária, considerando que o Distrito de Hamburgo, na qualidade de cessionário dos direitos de alimentos, poderia recorrer ao foro estabelecido no art. $3^{\circ}$, al. b). O caso chega ao Supremo Tribunal Federal alemão, que submete ao TJUE a questão relativa à interpretação do art. $3^{\circ}$, al. b) do Regulamento sobre Obrigações Alimentares, inquirindo se uma entidade pública que atribui prestações sociais a um credor de alimentos e, em resultado disso, por sub-rogação legal lhe é transmitido esse crédito, pode beneficiar do foro da residência habitual do credor de alimentos numa ação de regresso relativa ao crédito de alimentos contra o devedor de alimentos.

Ora, o caso que agora comentamos envolve a aplicação de uma norma de jurisdição presente no art. $3^{\circ}$ do Regulamento Sobre Obrigações Alimentares. Passemos a analisar, muito brevemente, o seu âmbito de aplicação.

\section{O Regulamento Sobre Obrigações Alimentares}

4. O Regulamento Sobre Obrigações Alimentares foi elaborado com o objetivo de permitir que a decisão que um credor de alimentos obteve num Estado-Membro tenha automaticamente força executória no espaço da União Europeia (considerando 9), permitindo a cobrança efetiva e célere deste tipo de créditos. Para esse efeito estabelece normas de competência internacional, normas de conflitos, e simplifica o procedimento de reconhecimento e execução das decisões relativas a alimentos.

5. O Regulamento n. ${ }^{0}$ 4/2009 aplica-se às obrigações alimentares decorrentes de relações de família, de parentesco, de casamento ou de afinidade (art. $1^{\circ}, \mathrm{n} .^{\circ} 1$ ), sendo que o conceito de obrigação alimentar deve ser interpretado de forma autónoma (considerando 11), para que exista um tratamento uniforme de todos os credores de alimentos dentro da União. Se assim não fosse, poderia existir uma desigualdade entre credores de alimentos dentro da União em situações idênticas, em resultado do conceito de obrigação alimentar ser diferente de Estado-Membro para Estado-Membro.

6. Decisão é entendida num sentido amplo de qualquer decisão proferida por um tribunal num Estado-Membro independentemente da sua designação como acórdão, sentença, despacho judicial, mandato de execução (artigo 2. $\left.{ }^{\circ}, n^{\circ} 1,1\right)$. O Regulamento aplica-se não só às decisões judiciais relativas às obrigações alimentares, como àquelas proferidas pelas autoridades administrativas dos EstadosMembros, desde que estejam salvaguardadas as garantias de imparcialidade dessas entidades e de au-

${ }^{1}$ STJCE 17 setembro 2020, C-540/19, Wv contra Landkreis Hamburg, 2020, ECLI:EU:C:2020:732. 
dição das partes (artigo 2. ${ }^{\circ}$, n. $^{\circ}$ 2). É também assegurado nos termos do Regulamento o reconhecimento e a execução das transações judiciais e dos atos autênticos (considerando 13 e artigo $48 .^{\circ}$ ).

7. O Regulamento aplica-se sempre que o tribunal de um Estado-Membro tenha competência segundo as normas de competência previstas no regulamento, sendo reconhecidas as decisões proferidas ao abrigo do mesmo.

8. Quanto ao seu âmbito de aplicação temporal, de acordo com o art. $76^{\circ}$ do Regulamento (CE) n. ${ }^{\circ} 4 / 2009$, este é aplicável a partir de 18 de junho de 2011, sob condição de nessa data o Protocolo de Haia de 23 de novembro de 2007 sobre a Lei Aplicável às Obrigações Alimentares (Protocolo de Haia) já ser aplicável na União. Todavia, o art. $4^{\circ}$ da decisão do Conselho 2009/941/CE, de 30 de novembro, relativa à celebração pela Comunidade Europeia do Protocolo de Haia, de 23 de novembro de 2007, sobre a lei aplicável às obrigações alimentares estabeleceu que as normas do referido Protocolo são aplicadas na União a título provisório a partir de 18 de junho de 2011, se este ainda não tivesse entrado em vigor nesta data.

9. O Regulamento sobre Obrigações Alimentares substituiu as disposições do regulamento Bruxelas I em matéria de obrigações alimentares (art. 68 ${ }^{\circ}$, n. ${ }^{\circ}$ 1) e do Regulamento (CE) n. $.^{\circ} 805 / 2004$, salvo em relação aos títulos executivos europeus emitidos num Estado-Membro não vinculado pelo Protocolo de Haia (art. $68^{\circ}$, n. $\left.^{\circ} 2\right)$.

\section{A norma de competência internacional do art. $3^{\circ}$ do Regulamento Sobre Obrigações Alimen- tares}

10. O caso que estamos a comentar versa sobre a interpretação de uma das alíneas do art. $3^{\circ}$, que é a norma de competência internacional supletiva, aplicável na ausência da existência de pactos atributivos de jurisdição ou caso estes não sejam possíveis, nos termos do art. $4^{\circ}$ do Regulamento sobre Obrigações Alimentares.

11. No art. $3^{\circ}$ encontramos uma norma de competência internacional que estabelece mais do que um tribunal competente para julgar uma ação relativa a direito de alimentos. A alternatividade dos fatores de competência estabelecida permite àquele que prevenir a jurisdição a oportunidade de escolha: o autor da ação poderá escolher um dos foros indicados na norma.

De acordo com a al. a) da referida disposição legal, terá competência para julgar uma ação de alimentos o tribunal do local da residência habitual do requerido. Esta norma concretiza o princípio do actor sequitur forum rei, ou seja, o princípio do tribunal da residência habitual do demandado.

12. Todavia, estamos perante uma norma de competência alternativa, por isso, o autor pode optar por propor a ação no tribunal do local da residência habitual do credor de alimentos. Esta norma da al. b) tem como efeito o favorecimento do credor de alimentos, uma vez que estabelece um forum actoris, no sentido em que, geralmente, o credor de alimentos será o autor da ação e poderá propor a ação no tribunal da sua residência habitual. Este é um foro que lhe será próximo e evitará as despesas e os incómodos de litigar em país estrangeiro.

13. Porém, o autor tem mais opções. De acordo com a al. c), tem ainda competência para apreciar a ação de alimentos o foro competente para apreciar uma ação relativa ao estado das pessoas (como o divórcio ou a validade do casamento) de acordo com a lex fori, quando o pedido de alimentos for acessório a essa ação. Só assim não será quando a competência se basear unicamente na nacionalidade de uma das partes, já que a nacionalidade de apenas uma parte não é considerado vínculo suficiente para atribuir competência internacional a um Estado. Este é um fator de competência que tentar concentrar a decisão de questões conexas no mesmo tribunal e permitir que sejam apreciadas em conjunto. Além de 
permitir a coerência na decisão de questões conexas, este fator de competência permite ganhos processuais e traduz uma boa administração da justiça, já que traz vantagens no plano da economia e celeridade processual, como por exemplo a apreciação de provas comuns. Beneficia também as partes, uma vez que lhes permite resolver todos os litígios no mesmo tribunal, evitando os custos e os incómodos da proliferação de ações conexas pelos tribunais de diferentes Estados. Esta norma permite uma articulação com o Regulamento n. ${ }^{\circ}$ 2201/2003 relativo à competência, ao reconhecimento e à execução de decisões em matéria matrimonial e em matéria de responsabilidade parental (Bruxelas II bis) ${ }^{2}$.

14. Por fim, o autor pode escolher propor a ação ainda no tribunal competente para apreciar uma ação relativa à responsabilidade parental de acordo com a lex fori, quando o pedido de alimentos é acessório a essa ação, nos termos da al. d). Só não será assim, quando a competência se baseia unicamente na nacionalidade de uma das partes. Tal como na al. c), a justificação desta disposição legal reside no facto de se possibilitar a decisão de questões conexas no mesmo tribunal e permitir que sejam apreciadas em conjunto, com as vantagens enunciadas supra. Nesta al. d) junta-se outra justificação de elevada importância. As ações judiciais que envolvem crianças, pelas regras de experiência comum, sujeitam a criança a episódios traumáticos. Possibilitar que seja o mesmo tribunal a decidir as responsabilidades parentais e a obrigação de alimentos, além de promover uma coerência de decisões, permite evitar sujeitar a criança a duas ações judiciais, com os efeitos nefastos que daí decorrem, e tomar uma decisão mais rápida relativamente a questões que são essenciais para a vida da criança. Desta forma, podemos reconhecer nesta alínea a concretização do princípio do superior interesse da criança. Também aqui temos uma articulação com o Regulamento Bruxelas II bis $^{3}$.

Note-se, ainda em relação ao art. $3^{\circ}$, que o conceito de nacionalidade deve ser substituído por domicílio, nos países que utilizem o domicílio como fator atributivo de competência em matéria familiar (art. $2^{\circ}$, n. $^{\circ}$, do Regulamento sobre Alimentos).

\section{A controvérsia em torno da al. b) do art. $3^{\circ}$ do Regulamento Sobre Obrigações Alimentares}

15. A controvérsia que é dirimida no julgamento que estamos a comentar é sobre a possibilidade de uma entidade pública recorrer ao tribunal do lugar da residência habitual do credor de alimentos, de acordo com o art. $3^{\circ}$ al. b), numa ação de regresso contra o devedor de alimentos relativa ao crédito de alimentos que lhe foi transmitido por sub-rogação legal, em resultado da atribuição de assistência social.

16. A questão levantou-se porque, antes da existência do Regulamento Sobre Obrigações Alimentares, a determinação do tribunal competente para julgar estas questões era feita, primeiro, segundo o art. $5^{\circ}$, n. $^{\circ}$ 2, da Convenção de Bruxelas, de 1968, relativa à competência judiciária, ao reconhecimento e à execução de decisões em matéria civil e comercial (Convenção de Bruxelas) e, posteriormente, quando surgiu o Regulamento n. ${ }^{\circ} 44 / 2001$ relativo à competência judiciária, ao reconhecimento e à execução de decisões em matéria civil e comercial (Regulamento Bruxelas I) pelo seu art. $5^{\circ}$, n. $^{\circ} 2$. Ambas as normas, entre outros fatores de jurisdição, atribuíam competência ao tribunal da residência habitual do credor de alimentos. Tendo sido chamado a interpretar o art. $5^{\circ}$, n. $^{\circ} 2$, da Convenção de Bruxelas no caso Freistaat Bayern e Jan Blijdenstein, o TJUE limitou a possibilidade de invocar este foro apenas àquelas situações em que o credor de alimentos era pessoalmente o demandante ${ }^{4}$. Vários foram os argumentos utilizados pelo Tribunal. Em primeiro lugar, foi considerado que o art. $5^{\circ}$, n. $^{\circ} 2$, era uma exceção à regra geral que atribuía competência ao tribunal do domicílio do réu, devendo, por isso, ter

\footnotetext{
${ }^{2}$ Para mais desenvolvimento, v. L. WALKER, Maintenance and Child Support in Private International Law, Oxford and Portland, Bloomsbury, 2015, p. 55; J. Carrascosa GonzÁlez, "Alimentos", em A.L. Calvo Caravaca/ J. Carrascosa GonzÁlez (Coord.), Derecho Internacional Privado, Vol. II, 17 Ed., Granada, Editorial Comares, 2017, p. 661.

${ }^{3}$ Para mais desenvolvimento, v. L. Walker, Maintenance and Child Support in Private International Law, Cit., p. 55; J. Carrascosa GonzÁlez, "Alimentos", Cit., p. 662.

${ }^{4}$ STJCE 15 de janeiro de 2004, C-433/01, Freistaat Bayern e Jan Blijdenstein, 2004, ECLI:EU:C:2004:21, §28.
} 
uma interpretação restritiva ${ }^{5}$. Em segundo lugar, o Tribunal olhou para a ratio do art. $5^{\circ}$, n. $^{\circ} 2$, enquanto norma que estabelecia uma competência alternativa à regra geral, justificando este forum actoris como visando um objetivo de proteção do credor de alimentos, enquanto parte mais fraca, já que este seria, em princípio, o requerente de alimentos ${ }^{6}$. Ora, estando em causa um organismo público que propõe uma ação de regresso, considerou o Tribunal que este não estaria numa posição de inferioridade em relação ao devedor, e o credor de alimentos, tendo já a sua situação acautelada, também já não estaria numa posição precária ${ }^{7}$, não se justificando que aquele organismo público pudesse recorrer ao art. $5^{\circ}$, n. $^{\circ} 2$. Esta ideia de que a jurisdição da residência habitual do credor de alimentos como tendo como objetivo a proteção do mesmo enquanto parte mais fraca quando este é o requerente já resultava de outras decisões e continuou a ser sublinhada posteriormente pelo Tribunal ${ }^{8}$. Em terceiro lugar, foi considerado que o tribunal do domicílio do demandado (regra geral do art. $2^{\circ}$ ) era o foro que estava melhor localizado para apurar os recursos financeiros daquele ${ }^{910}$.

17. Aquando do surgimento do Regulamento Sobre Obrigações Alimentares, o TJUE adotou a posição que a interpretação das normas de competência internacional deste Regulamento deveria tomar em consideração a jurisprudência deste Tribunal relativas às disposições legais presentes na Convenção de Bruxelas e no Regulamento Bruxelas $\mathrm{I}^{11}$.

18. No acórdão que estamos a analisar, o TJUE é chamado a interpretar o fator de competência residência habitual do credor de alimentos agora no sistema do Regulamento Sobre Obrigações Alimentares, tendo decidido inverter a sua jurisprudência. No caso Wv contra Landkreis Hamburg, o Tribunal decide que a entidade pública que propõe uma ação de regresso contra um devedor de alimentos para a cobrança de um crédito pago a título de alimentos a um credor de alimentos, em sub-rogação destes direitos, pode recorrer ao art. $3^{\circ}$, al. b) e propor a ação no tribunal da residência habitual daquele credor. Para justificar esta opção, o Tribunal utiliza vários argumentos que passamos a analisar.

19. Desde logo, interpretando o art. $3^{\circ}$ de acordo com a sua redação, as suas finalidades e o sistema em que se insere, o Tribunal afirma que a redação do art. $3^{\circ}$, ao contrário do que sucedia na Convenção de Bruxelas, não apresenta uma regra geral e uma exceção, que justifique uma interpretação restritiva ${ }^{12}$. Pelo contrário, encontramos nesta norma fatores de jurisdição alternativos e o autor da ação pode optar por qualquer um deles. De facto, analisando a redação da norma, encontramos fatores de competência alternativos, sem existir qualquer hierarquia entre os mesmos.

20. Outro argumento relacionado com a redação da norma prende-se com o facto de esta não reservar o recurso à al. a) ou b) do art. $3^{\circ}$ ao próprio credor de alimentos ${ }^{13}$. É incontornável que a redação da norma não se pronuncia sobre esta questão, o que implica a necessidade de recorrermos aos objetivos e a uma interpretação sistemática da norma para resolvermos a questão.

21. Ora, neste seguimento, considerou o Tribunal que tanto os objetivos e o sistema do Regulamento não se opunham a que uma entidade pública nas circunstâncias decididas no caso pudesse

\footnotetext{
${ }^{5}$ Idem, ibidem, $\S 25$.

${ }^{6}$ Idem, ibidem, $\$ 29$.

${ }^{7}$ Idem, ibidem, $\$ 30$.

${ }^{8}$ STJCE, 20 de Março de 1997, C-295/95, Jackie Farrell e James Long, Rec 1997 I-01683, §19; STJCE 18 dezembro 2014, C-400/13, C-408/13, Sophia Marie Nicole Sanders, representada por Marianne Sanders, contra David Verhaegen, e Barbara Huber contra Manfred Huber, 2014, ECLI:EU:C:2014:2461, § 28.

${ }^{9}$ STJCE 15 de Janeiro de 2004, C-433/01, Freistaat Bayern e Jan Blijdenstein, 2004, ECLI:EU:C:2004:21, §31.

${ }^{10}$ Sobre os beneficiários desta opção e as críticas da doutrina à interpretação restritiva do TJUE, V. H. GAUDEMET-TALLON, Compétence et exécution des jugements en Europe, 5e Ed., Paris, LGDJ, 2015, p. 263-264, incluindo o facto desta interpretação restritiva não se coadunar com as normas de sub-rogação e cessão de créditos da maioria dos Estados-Membros.

${ }^{11}$ STJCE 18 dezembro 2014, Sophia Marie Nicole Sanders, Cit., § 23.

${ }^{12}$ STJCE 17 setembro 2020, C-540/19, Wv contra Landkreis Hamburg, 2020, ECLI:EU:C:2020:732, §28-29.

${ }^{13}$ Idem, ibidem, $§ 31$.
} 
recorrer ao tribunal do credor de alimentos. No plano dos objetivos do Regulamento, o TJUE chamou à colação o princípio de proximidade entre o tribunal e o credor de alimentos e o objetivo de facilitar a cobrança internacional de alimentos (presente do considerando 45 do Regulamento) ${ }^{14}$. Não podemos deixar de concordar ${ }^{15}$, sobretudo tendo em consideração este último objetivo, que não permitir que a referida entidade pública recorresse à al. b), do art. $3^{\circ}$, acarretaria que esta ficaria limitada ao tribunal da residência habitual do devedor de alimentos. Isto implicaria, regra geral, propor uma ação no estrangeiro com as dificuldades e custos resultantes. Quando aquela residência se situasse num Estado terceiro, a ação teria que ser proposta nesse Estado terceiro, com todos os problemas daí resultantes, pondo em causa o objetivo do Regulamento de facilitar a cobrança internacional de alimentos. Além de outros obstáculos $^{16}$, a decisão final já não seria reconhecida e executada ao abrigo do sistema automático do Regulamento sobre Obrigações Alimentares.

22. Outro argumento utilizado baseou-se no princípio da boa administração da justiça e no interesse processual das partes, devendo estas ter um acesso facilitado à justiça, através de regras de competência previsíveis. Em primeiro lugar, foi considerado que a previsibilidade das regras de competência internacional estavam salvaguardadas uma vez que o devedor de alimentos deve esperar ser demandado quer no foro da sua residência habitual, quer no foro da residência habitual do credor ${ }^{17}$. Em segundo lugar, o facto de uma entidade pública sub-rogada nos direitos do credor de alimentos poder recorrer ao art. $3^{\circ}$, al. b) foi considerado como respeitando uma interpretação sistemática do Regulamento ${ }^{18}$. Não podemos deixar de concordar com este raciocínio. Se é verdade que o art., $2^{\circ}$, n. $^{\circ} 2$ (10) estabelece que credor de alimentos para efeitos do regulamento é qualquer pessoa singular à qual são devidos ou se alega serem devidos alimentos, o considerando 14 estabelece que para efeitos de reconhecimento e execução de decisões em matéria de obrigações alimentares, credor inclui «(...) os organismos públicos habilitados a atuar em nome de uma pessoa a quem sejam devidos alimentos ou a solicitar o reembolso das prestações fornecidas ao credor a título de alimentos (...)». Será o caso dos fundos de garantia que existam nos Estados-Membros. O art. $64^{\circ}$ concretiza este considerando no seu n. ${ }^{\circ}$ 1, equiparando os fundos de garantia de alimentos ao credor para efeitos de um pedido de reconhecimento e de declaração de força executória ou de execução de decisões, e no seu n. ${ }^{\circ}$ 3, onde se estabelece inclusive na al. a) que uma entidade pública em sub-rogação dos direitos de alimentos do credor pode requerer o reconhecimento e a declaração de força executória ou a execução de uma decisão proferida contra um devedor numa ação de regresso de prestações fornecidas em lugar de alimentos. Ora, considerou o Tribunal, de forma correta em nossa opinião, que esta alínea do art. $64^{\circ}, \mathrm{n}^{\circ}{ }^{\circ} 3$, implica que a referida entidade pública tenha podido recorrer ao tribunal referido na al. b) do art. $3^{\circ}$ para este adotar uma decisão nos termos do art. $2^{\circ}$, n. $^{\circ} 1(1)^{19}$.

23. O último argumento utilizado pelo Tribunal residiu na coerência com o Protocolo da Haia, de 23 de novembro de 2007, sobre a Lei Aplicável às Obrigações Alimentares (Protocolo da Haia), aplicável por força do art. $15^{\circ}$ do Regulamento. $\mathrm{O}$ art. $3^{\circ}$ do Protocolo de Haia manda aplicar às obrigações alimentares a lei da residência habitual do credor de alimentos. Da mesma forma o art. $10^{\circ}$ do Protocolo estabelece que o direito de reembolso de um organismo público em resultado de uma prestação dada ao credor de alimentos resulta da lei que regula esse organismo público, o que é reiterado pelo art. $64^{\circ}$, n. ${ }^{\circ} 2$ do Regulamento. Desta forma, como na maioria dos casos a lei que rege os referidos organismos públicos é aquela onde se situa a residência habitual do credor de alimentos, esta posição permite a coincidência entre o tribunal competente e a lei aplicável ${ }^{20}$. Não podemos deixar de reconhecer que a coincidência forum/ius facilita a resolução do litígio.

\footnotetext{
${ }^{14}$ Idem, ibidem, $\S 33$.

${ }^{15}$ Idem, ibidem, $\$ 35$.

${ }^{16}$ Com referência a estes obstáculos v. Conclusões do Advogado-geral Manuel Campos SÁNCHEZ-BORDON, apresentadas em 18 de junho de 2020, C-540/19, ECLI:EU:C:2020:484, §42.

${ }^{17}$ TJUE 17 setembro 2020, C-540/19, Wv contra Landkreis Hamburg, Cit., §38.

${ }^{18}$ Idem, ibidem, §39-42.

${ }^{19}$ Idem, ibidem, $\$ 41-42$.

${ }^{20}$ Idem, ibidem, $\$ 43$.
} 
24. Adicionamos aos referidos argumentos do Tribunal, que esta interpretação protege o credor, um dos objetivos do art. $3^{\circ}$, al. b), na medida em que o devedor terá um incentivo para cumprir as suas obrigações $^{21}$. Ou seja, é uma interpretação que não vai beneficiar a parte incumpridora. É uma interpretação que, razoavelmente, protege também os fundos de garantia dos Estados-Membros. Estes concedem prestações de alimentos para assegurar um rendimento de sobrevivência aos credores de alimentos que são abandonados por aqueles que têm o dever de cuidar destes, mas, posteriormente, até por uma questão de sustentabilidade financeira, estes organismos públicos precisam de recuperar as prestações pagas, com alguma celeridade. Seria um contrassenso dificultar-lhes o direito de reembolso, limitando o foro a que podem recorrer à residência habitual do devedor, empurrando-os para litígios sistemáticos em país estrangeiro, com os obstáculos, custos e onerosidade daí resultante. Esta situação seria mais grave, quando a residência habitual do devedor se situasse num Estado terceiro. Estas dificuldades poderiam desencorajar estas entidades a tentar recuperar as prestações pagas, sobretudo quando os valores fossem reduzidos, e in extremis pôr em causa o pagamento destas prestações de alimentos. O argumento de que o credor de alimentos já não está numa posição de inferioridade, porque a sua situação foi acautelada pela intervenção do fundo de garantia ${ }^{22}$, não nos parece que deva colher. Não está numa posição de inferioridade, porque o fundo de garantia interveio em lugar de quem estava obrigado a fazê-lo. Logo, a intervenção do fundo de garantia deve ser valorizada e a sua posição salvaguardada, não se justificando a proteção do devedor de alimentos que não cumpriu a sua obrigação. Adicionalmente, as razões de justiça e o objetivo de facilitar a cobrança internacional de alimentos, presentes na opção legislativa dos fatores de competência alternativa do art. $3^{\circ}$, mantêm-se quer o requerente seja o credor, quer seja um organismo público em sub-rogação dos direitos do credor pedindo o reembolso pelas prestações pagas a título de direito de alimentos.

25. Tendo em consideração o exposto, a inversão da jurisprudência do TJUE no caso $W v$ contra Landkreis Hamburg, no sentido de uma entidade pública recorrer ao tribunal do lugar da residência habitual do credor de alimentos, de acordo com o art. $3^{\circ}$ al. b), numa ação de regresso contra o devedor de alimentos relativa ao crédito de alimentos que lhe foi transmitido por sub-rogação legal, parece-nos configurar uma interpretação teleológica, de acordo com os objetivos da norma e do Regulamento, e uma interpretação sistemática, tendo em consideração outras normas do Regulamento e do Protocolo de Haia. Assim, não podemos deixar de elogiar a posição do TJUE, por concluir que a estrutura e sistema do Regulamento sobre Obrigações Alimentares, na questão apreciada, não permitem manter a continuidade interpretativa com a jurisprudência anteriormente elaborada para efeitos do Regulamento Bruxelas I.

\footnotetext{
${ }^{21}$ Também com este argumento v. Conclusões do Advogado-geral Manuel Campos SÁNCHEZ-BORDON, apresentadas em 18 de junho de 2020, C-540/19, ECLI:EU:C:2020:484, §58.

${ }^{22}$ Utilizado pelo STJCE no caso Freistaat Bayern e Jan Blijdenstein como referido supra.
} 